\title{
Science Learning in Augmented Reality Context: An Exploration of Learners' Cognitive Load and Attitudes
}

\author{
Prof. Nabil Abdel Wahed Fadl ${ }^{1}$, Wafaa Abd Al Monem Youssef ${ }^{2}$ \\ ${ }^{1}$ Professor of Curricula \&science Instruction, Faculty of Education, Tanta University, Egypt \\ ${ }^{2} \mathrm{PhD}$ Researcher Curricula \&science Instruction Faculty of Education, Tanta University, Egypt
}

\begin{abstract}
The Current Study Investigates The Use of Augmented Reality (AR) Technology In Science Learning By Means of A Quantitative Survey Using Two Questionnaires. In Fact, This Study Explores Perceived Cognitive Load, and Attitudes among 106 Students of Second Preparatory Grade (35) Students Learned Science with Augmented Reality Context, and (71) Students Learned Science with Traditional Method. The Findings Manifested That, In General, The AR Students Perceived Less Cognitive Load And Attained More Positive Attitudes Towards The Experiences. The Perceived Usefulness And Easiness of Use Play A Role In The Intentions To Take Part In Future AR Learning, And Effect On The Attitude Toward Using AR Environments.
\end{abstract}

Keywords: Augmented Reality, cognitive load, Acceptance Model, Attitude toward Using, Intention to Use

\section{Introduction}

In essence, computer and communication technologies have deeply changed our everyday life. Earlier, great expectations for improving education emerged. The 2011 Horizon Report, AR, with its layering of information over $3 \mathrm{D}$ space, makes new experiences of the world, and stated that AR should be applied in the next (2-3) years to offer new chances for teaching, learning, research, or scientific research. AR makes use of virtual objects or information overlaying physical objects or environments, leading to a mixed reality in which virtual objects and real environments are found in the same context meaningfully to augment learning experiences. (Johnson, Smith, Willis, Levine, \& Haywood, 2011) There are a plethora of domains useful for using AR technology such as advertising and marketing, architecture and construction, entertainment, medical, military, travel and education (Squire \& Klopfer, 2007) .

What is Augmented Reality AR?

(Azuma \& et al., 2001) crystalize AR, basing on three characteristics:

- The mixture of real and virtual objects in a real-life environment.

- Runs interactively and in real time.

- Gathers real and virtual objects with each other.
- This identification stresses the real environment as the place where virtual objects are found. This is a seminal difference with respect to Virtual Reality (VR), where the user mainly relates to a virtual environment.

\section{AR technology}

Classifies AR technologies in the following three types, (1) mobile devices, suchlike as Smartphone and Tablet, (2) stationary units and (3) head mounted display. Mobile devices are cheap and available in many fields, making it possible to exploit the technology in schools. ( Swensen, 2016). AR applications are classified as marker-based and location-based applications. Location-based applications consisted of 3 parts as monitoring systems, devices that diagnose area and image. For the marker-based applications, they include 3 basic components such as a manual with the marker in it, a gear that alters the data in the marker into digital data and a display unit which screens the digital data in $3 \mathrm{D}$ or $2 \mathrm{D}$ format ( Küçük, \& Gökta, 2014).

VR versus AR:

There is a Simple Comparison Between the Following Elements (Fernandez, 2017).:

Virtual reality runs over new environments wholly computer based. That entire user can handle, touch, or interact with is virtual. Augmented reality exploits virtual elements only 
to increase the real world and the user's experience. Virtual reality replaces the physical world. However, augmented reality does not

- The level of involvement of virtual reality is $100 \%$. Users are fully separated from the real/physical world. Users are in a full connection with the physical world by means of augmented reality. Users are fully aware of their surroundings and can perceive, touch, and interact with the real world assisted by all the digital information the application offers.

- Virtual reality requires a very powerful processor. New applications are being initiated using mobile phone processors, but they are very limited in number. Quality is noticeably different from other devices such as Oculus Rift or HTC Vive. It is agreed that augmented reality can provide interesting services through tablets or mobile phones. It is seminal to consider that augmented reality is not only (Microsoft HoloLens or Meta 2), dedicated devices which are highly demanding. Examples of other augmented reality applications are mobile phones with a full range of features.

- In sum, virtual reality is $10 \%$ real and $90 \%$ virtual. Augmented reality is $75 \%$ real and $25 \%$ virtual. It is crystal clear that the percentages depend on the application. They are general estimations based on current market applications.

Figure (1) Manifests The Relative Position of AR In The Continuum of Reality Environments And The Overall Relationship Between Reality, Virtuality And Augmentation.(Milgram \& Kishino, 1994). (Salmi, Kaasinen, \& Kallunki, 2012) Website.

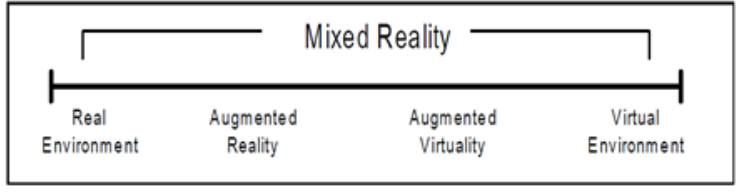

Fig. (1) Milgram's Reality- Virtuality Continuum

Paul Milgram and Fumio Kishino identified Milgram's Reality- Virtuality Continuum in 1994. They explain a continuum that runs from the real environment to a pure virtual environment. In between there are Augmented Reality (closer to the real environment) and Augmented Virtually (is closer to the virtual environment), as seen in (Fig. 1)

\section{AR and science Education}

Primarily, science includes many dynamic concepts that are too difficult to explain in traditionally by means such as still slides. For this reason, animations are advantageous for delivering better representations of these concepts. In other words, animations are good supplementary learning materials for students particularly for learning of complicated concepts (Hwang, (TAM), Lam, \& Lam, 2012). (Wu, Lee, Chang, \& Liang, 2013) Stressed that AR systems can support learners in visualizing abstract science concepts, specifically noting the following potentials:

- learning content in (3D) perspective

- ubiquitous, collaborative and situated learning

- learners' sense of presence, immediacy, and immersion

- visualizing the invisible

- Bridging formal and informal learning.

A recent study (Almenara, Fernandez-Batanero, \& Osuna, 2019) illustrated that AR Could offer different potentials such as:

a) Abolishing the information that could prevent the capturing of vital information by the student.

b) The increasing or enriching of the information from reality to make it more comprehensible for the student.

c) The ability to observe an object from different points of view, with the student selecting when and the point of views themselves.

d) To support ubiquitous learning.

e) Making safe "artificial" scenarios for students, such as laboratories or simulators.

f) Enriching the printed material for the students with more information in different forms.

g) Paying the students' attention to "pro-consumers" of learning objects in AR format.

h) Can be used in training activities based on the Flipped Classroom methodology.

i) Informal learning is supported.

j) Augmented reality and cognitive load

The theory specifies three different types of cognitive load (Shibli, 2018):

- Intrinsic cognitive load: the existing difficulty of the material itself, which can be influenced by previous knowledge of the topic

- Extraneous cognitive load: the load emerged by the way the material is presented and which does not aid learning

- Germane cognitive load: the elements that aid information processing and contribute to the development of 'schemas'

Multimedia learning environments effects the cognitive loads of individuals as well. As (Paas, Renkl, \& Sweller, 2003) states. AR is rather different from traditional computer interfaces and has the ability to enhance learning materials, lessen extraneous cognitive load, and makes intrinsic and germane cognitive loads very easy (Slijepcevic, 2013). Well-designed AR applications can be 
exploited to create effective and efficiency learning environment that will provide low level cognitive load and high level achievement to students. ( Küçük, Yýlmaz, \& Gökta, 2014)

\section{Augmented reality and attitudes}

It is widely acknowledged that the process of adapting new technologies by learners is primarily related to their attitudes. The studies based on technology acceptance model ((TAM)) (Davis, 1989) have stated that learners show positive attitudes when they perceive the new technologies like (AR) will be easy to use and useful (Chang, Chen, Huang, \& Huang, 2011). (TAM) is generally used to explain how a company and individual respond and adapt to a new technology. The (TAM) put that willingness to accept and adopt new technologies is determined immediately by the attitude, usability and ease of use. According to (TAM), a person's intention to use technology determines application usage and attitudes toward technology affect such intention Davis (Davis, 1989) defines perceived usefulness as the extent to which a person believes that his job performance would increase using a particular system. He also identifies perceived ease of use as the extent to which a person does not challenged by difficulties when using a particular system. (Sugara \& Mustika, 2016). the factor of perceived usefulness was underlined as playing a significant role in students' learning by AR technology. ( Wojciechowski \& Cellary, 2013), when students involved in an AR book reading activity they perceived more positive attitudes towards the experiences, and they were inclined to learn with the aid of AR technology in the future, perceived usefulness play a role in their behavioral intentions to take part in future AR learning (Cheng, 2017).

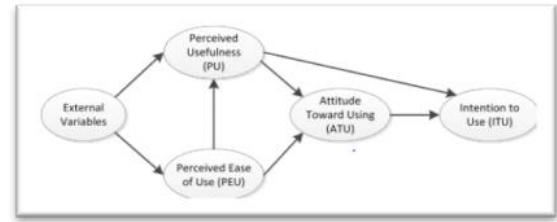

Fig. (2)Technology Acceptance Model ((TAM)).

\section{Methodology \& Procedure}

This study manipulated a Quasi-experimental research and AR approach to explore users' cognitive load, and attitudes when involved in the AR learning context Compared to the traditional approach. The augmented information was designed by (aurasma) app in the form of (3D) models and videos used along with some cards, Learners interact with virtual information by using a mobile device with a camera (e.g., a smart phone or tablet). The sample of the study is a group consisting of (106) students from the Coptic School in Tanta, affiliated to West Educational Administration in Tanta City, divided into (35) students representing the experimental group, and (71) students representing the control group

\section{The study tools were}

- Questionnaire for students after using AR approach: The questionnaire includes 3 levels on (Likert scale). These levels were as follows (1: disagree, 2: agree to somewhat, 3: agree). The two groups experienced the instructional processes for the periodicity of elements and properties Unit the first unit of the first term for the second preparatory grade.

- Survey for cognitive load: the study exploited the survey used in (Cheng, 2017) study. The cognitive load survey was originally developed by (Sweller, 1989), there are two scales of mental effort and mental load in the survey. From one hand, mental effort (ME) measures the extent of an individual's invested cognitive capacity when trying to process information presented in the AR approach. On the other hand, mental load (ML) measures the extent of the cognitive capacity which is needed to process the information in the AR approach.

- Survey for attitudes: The items for attitudes Survey were adopted from (Cheng, 2017), and ( Wojciechowski \& Cellary, 2013).The attitudes Survey developed originally from (TAM) model, The constructs in this study consisted of Perceived Usefulness (PU), Perceived Easy of Use (PEU), Attitude toward Using (ATU) and Intention to Use (ITU).

(Alpha Cronbach) value was presented in Table 1. was calculated to measure the internal consistency among statements. The statements considered reliable if the value was greater than (0.6). (Sugara \& Mustika, 2016) . (Alpha Cronbach) had values which varied from (0.680) to $0.806 \backslash$ ML had the smallest value (0.680) while ITU had the biggest one (0.806), the total value is $(0.854)$. Based on the result which greater than 0.6 , all statements are considered reliable and could be used in the questionnaire

Table. (1) Alpha Cronbach Values for All Measurements

\begin{tabular}{|c|c|c|c|}
\hline \multicolumn{2}{|r|}{ Construct } & $\begin{array}{l}\text { Number } \\
\text { Of Items }\end{array}$ & $\begin{array}{l}\text { alpha } \\
\text { Cronbach }\end{array}$ \\
\hline \multirow{2}{*}{$\begin{array}{l}\text { cognitive } \\
\text { load }\end{array}$} & Mental Effort(ME) & 2 & 0.699 \\
\hline & Mental Load(ML) & 2 & 0.680 \\
\hline \multirow{4}{*}{ Attitudes } & Perceived Usefulness (PU) & 5 & 0.761 \\
\hline & Perceived Easy of Use(PEU) & 4 & 0.721 \\
\hline & Attitude toward Using(ATU) & 5 & 0.738 \\
\hline & Intention to Use(ITU) & 4 & 0.806 \\
\hline Total & & 22 & 0.854 \\
\hline
\end{tabular}

\section{Results}

Cognitive load: The aim of using the cognitive load measure was to evaluate whether the students' performances were affected owing to improper 
educational settings, including the difficulty levels of the selected AR learning materials. The cognitive load measurement consisted of two dimensions: mental load and mental effort. An in-depth analysis was further conducted on these two dimensions. Mental effort refers to whether the students must exert more mental effort to understand the learning materials. Table 2 shows the experimental group's $($ mean $=3.11)$ and $(\mathrm{SD}=1.02)$ while the controlling group's (mean $=4.65)$ and $(\mathrm{SD}=1.06)$ The t-test analysis results showed that $(\mathrm{t}=7.18, \mathrm{p}>.05)$ indicating to significant difference between the mental effort of the two groups in favor of the control group; it means mental effort of the students who learned with the mobile AR approach is lower than that of the controlling group.

Mental load: refers to the internal aspects of cognitive load; specifically, when students face a large amount of learning content or difficult content beyond their information processing abilities or knowledge levels, they may perceive an excessive cognitive load. For mental load, Table 2 shows the experimental group's (mean $=3$ ) and $(\mathrm{SD}=1.21)$ while the controlling group's (mean $=$ 3.92) and $(\mathrm{SD}=1.42)$ The t-test results showed that $(\mathrm{t}$ $=3.45, \mathrm{p}>05)$ which indicates significant difference between the mental load of the two groups, in favor of the controlling group. The control group perceive greater mental load when processing science information rather than students of the experimental group. This indicates that AR applications are able to Reducing the load of difficult science content. The results also indicate that the mental load of the experimental group's mean (3) is approximately equal to mental effort of Experimental group's mean (3.11), meaning that the cognitive ability required to process science information with $\mathrm{AR}$ applications is approximately equal to the effort exerted by students during learning, and AR applications do not generate any additional cognitive load.

Table 2. T-test results of the two subscales of cognitive load of the two groups

\begin{tabular}{|l|l|l|l|l|l|}
\hline Variable & Group & $\mathbf{N}$ & Mean & S.D. & T \\
\hline Mental effort & $\begin{array}{l}\text { Experimental } \\
\text { group }\end{array}$ & 35 & 3.11 & 1.02 & \multirow{2}{*}{7.18} \\
\cline { 2 - 5 } & Control group & 71 & 4.65 & 1.06 & \\
\hline Mental load & $\begin{array}{l}\text { Experimental } \\
\text { group }\end{array}$ & 35 & 3 & 1.21 & \multirow{2}{*}{3.45} \\
\cline { 2 - 5 } & Control group & 71 & 3.92 & 1.42 & \\
\hline
\end{tabular}

*p $<.05$

Attitudes: With regard to the students' attitudes toward AR approach, Table (3) presents the differences between the scales in the survey for attitudes:-

- From Table (3), the total experimental group's mean (58.11), $(\mathrm{SD}=5.251)$ while the controlling group's mean $(43.51)$, and $(\mathrm{SD}=8.668)$, the t-test results showed that $(\mathrm{t}=10.75, \mathrm{p}<.05)$, which indicates significant difference between the attitudes of the two groups in favor of the experimental group.

- Similarly, we note significant difference between the two groups in favor of the experimental group In all sub-axes (Perceived Ease of Use, Perceived Usefulness, Attitude toward using, Intention to Use) at $\mathrm{p}<.05$, and $\mathrm{t}=(8.93,9.09,4.21,9.75)$ respectively implying that the mobile AR approach can promote students' attitudes towards learning science.

- Arranging the means of the sub-axes of the experimental group as follows: the higher average was the Perceived Usefulness (13.57), followed by Attitude toward using (12.34), and followed by the Perceived Ease of Use (10.86) which is almost equal to the next axis intention to use (10.83). These results indicate that Perceived Usefulness of using the AR approach was one of the most important factors affecting the generation of a positive attitudes among students towards science.

- The Perceived Ease of Use experimental groups mean (10.86), and Controlling groups mean (7.65) that indicate students of the experimental group find it easier to use AR approach compared to the traditional method and they don't have difficulty in using the application.

- The perceived Usefulness and ease of use of the AR application helped to generate a great intention among experimental group students to use the AR application in the future (10.83) compared to the intention to use control group's mean (6.86).

- The low mean in intention to use of control group (6.86) indicates that a large group of students do not want to continue learning in the traditional way because it does not meet their needs.

Table 3. T-test results of the four subscales of learning attitudes for the two groups

\begin{tabular}{|c|c|c|c|c|c|}
\hline Variable & Group & $\mathbf{N}$ & Mean & S.D. & $\mathbf{t}$ \\
\hline \multirow[t]{2}{*}{ Perceived Ease of Use } & Experimental & 35 & 10.86 & 1.438 & \multirow[t]{2}{*}{$8.93^{*}$} \\
\hline & Control & 71 & 7.65 & 2.230 & \\
\hline \multirow[t]{2}{*}{ Perceived Usefulness } & Experimental & 35 & 13.57 & 1.313 & \multirow[t]{2}{*}{$9.09^{*}$} \\
\hline & Control & 71 & 10.14 & 2.571 & \\
\hline \multirow[t]{2}{*}{ Attitude toward using } & Experimental & 35 & 12.34 & 1.939 & \multirow[t]{2}{*}{$4.21^{*}$} \\
\hline & Control & 71 & 10.55 & 2.298 & \\
\hline \multirow[t]{2}{*}{ Intention to Use } & Experimental & 35 & 10.83 & 1.581 & \multirow[t]{2}{*}{$9.75^{*}$} \\
\hline & Control & 71 & 6.86 & 2.587 & \\
\hline \multirow[t]{2}{*}{ TOTAL } & Experimental & 35 & 58.11 & 5.251 & \multirow[t]{2}{*}{$10.75^{\star}$} \\
\hline & Control & 71 & 43.51 & 8.668 & \\
\hline
\end{tabular}

\section{Discussion}

In this study, a mobile (AR) approach is proposed for science learning. The experimental findings show that the mobile AR approach does not increase the cognitive loads 
of educational materials, and (AR) approach is able to reduce the effort of learners in information processing and reducing the load of difficult science content. Similar Studies accepted the (TAM) model could be considered adequate for understanding the degree of acceptance that a technology awakens in its potential users and their future intention of use as well. In this study the experimental results show that the mobile (AR) approach is able to promote students' attitudes towards learning science. The perceived Usefulness and ease of use to (AR) application helped to generate a great future intention of use. Perceived Usefulness in (AR) learning context is greater than Perceived Ease of Use application. Hence, students do not have difficulty using mobile AR applications and they find it is easy to use. This is because they are classified as digital age's students who can use modern technology effectively without any previous training. Thus, the creation of this type of learning objects should be promoted for their use in Preparatory teaching settings.

\section{Conclusion}

AR learning scenarios that present relevant materials (images- texts- videos - 3D models) can avoid creating incidental cognitive load, and hence benefits students in improving their learning performance, and provide high level Attitude to students. Thus, we can use of (AR) technology in linking the real-world contexts with the digital learning resources More widely and through different science learning educational stages.

\section{References}

[1] Almenara, J. C., Fernandez-Batanero, J. M., \& Osuna, J. B. (2019). Adoption of augmented reality technology by university students. Heliyon, 5.

[2] Azuma, R., \& et al. (2001). Recent advances in augmented reality. IEEE computer graphics and applications, 21, pp. 34-47.

[3] Chang, Y. J., Chen, C. H., Huang, W. T., \& Huang, W. S. (2011). Investigating students' perceived satisfaction, behavioral intention, and effectiveness of English learning using augmented reality. Proceedings of the 2011 IEEE International Conference on Multimedia and Expo, (pp. 16). Barcelona, Spain.

[4] Cheng, K.-H. (2017). Reading an augmented reality book: An exploration of learners'cognitive load, motivation, and attitudes. Australasian Journal of Educational Technology, 33(4).

[5] Davis, D. F. (1989). Perceived usefulness, perceived ease of use, and user acceptance of information technology. MIS Quarterly, 13(3), pp. 319-340. Retrieved from http://www.jstor.org/stable/249008

[6] Fernandez, M. (2017). Augmented Virtual Reality: How to Improve Education Systems. Higher Learning Research Communications, 7, pp. 1-15.

[7] Hwang, I., Tam, M., Lam, S. L., \& Lam, P. (2012). "Review of Use of Animation as a Supplementary Learning Material of Physiology Content in Four Academic Years". Learning, 10.
[8] Johnson, L., Smith, R., Willis, H., Levine, A., \& Haywood, K. (2011). The 2011 Horizon Report. Austin, Texas: The New Media Consortium.

[9] Küçük, S., Yýlmaz, R. M., \& Gökta, Y. (2014). Augmented Reality for Learning English: Achievement, Attitude and Cognitive Load Levels of Students. Education and Science, 39(176), pp. 393-404.

[10] Milgram, P., \& Kishino, F. (1994). A TAXONOMY OF MIXED REALITY VISUAL DISPLAYS. IEICE TRANSACTIONS on Information and Systems, 77(12), pp. 1321-1329.

[11] Paas, F., Renkl, A., \& Sweller, J. (2003). Cognitive load theory and instructional design: Recent developments. Educational Psychologist, 38, pp. 1-4.

[12] Salmi, H., Kaasinen, A., \& Kallunki, V. (2012). Towards an Open Learning Environment via Augmented Reality (AR): visualising the invisible in science centres and schools for teacher education. The 5th Intercultural Arts Education Conference: Design Learning (pp. 284 - 295). Procedia - Social and Behavioral Sciences 45.

[13] Shibli, D. (2018). Cognitive Load Theory and its application in the classroom. chartered college of teaching University of Hertfordshire.

[14] Slijepcevic, N. (2013). The effect of augmented reality treatment on learning, cognitive load, and spatial visualization abilities (Unpublished doctoral dissertation). . University of Kentucky, Lexington, KY.

[15] Squire, K., \& Klopfer, E. (2007). Augmented reality simulations on handheld computers. Journal of the Learning Sciences, 16(3), pp. 371-413. Retrieved from http://dx.doi.org/10.1080/10508400701413435.

[16] Sugara, E. P., \& Mustika. (2016). STUDENT ACCEPTANCE IN AUGMENTED REALITY COMPUTER HARDWARE LEARNING MEDIA. BANDUNG CREATIVE MOVEMENT 2016 , Multidisciplinary Design: Harmonizing design in today's society, technology and business.

[17] Sweller, J. (1989). Cognitive technology; some procedures for facilitating learning and problem solving in mathematics and science. Journal of Educational Psychology, 81(4), pp. 457-466.

[18] Swensen, H. (2016). POTENTIAL OF AUGMENTED REALITY IN SCIENCES EDUCATION A LITERATURE REVIEW. Proceedings of ICERI2016 Conference. Seville, Spain.

[19] Wojciechowski, R., \& Cellary, W. (2013). Evaluation of learners' attitude toward learning in ARIES augmented reality environments. Computers \& Education, 68, pp. 570-585.

[20] Wu, H., Lee, S., Chang, H., \& Liang, J. (2013). Current status, opportunities and challenges of augmented reality in. 